\title{
Chronic Secondary Otalgia: Multidisciplinary Evaluation and Relationship with Cervical Spine Disease
}

\begin{abstract}
Keywords: Cervical spine; Chronic secondary otalgia
Abstract

Objective: We developed an algorithm to evaluate secondary otalgia and examined the role of cervical spine disease in chronic secondary otalgia. Otalgia may arise from the ear itself (primary) or may indicate pathologies outside the ear (secondary). Secondary otalgia is a common and complex symptom.

Material and methods: We evaluated the etiological factors in 224 patients diagnosed with secondary otalgia from the perspectives of an otolaryngologist, neurologist, and dentist. We recorded data on the pathogenesis of the otalgia, patient age and gender, pain localization and period, and test results.

Results: The most frequent causes of chronic secondary otalgia were cervical spine disease $(n=110,49.5 \%)$, temporomandibular joint disorders $(n=72,32.1 \%)$, and dental pathologies $(n=49,21.9 \%)$. Of the patients, $31.3 \%(n=70)$ had more than one etiology. The most frequent pathology of cervical spine disease was cervical disc disease $(n=90$, $40.2 \%)$.

Conclusion: On considering secondary otalgia, in must first be separated into acute versus chronic. Cervical spine disease is the most common cause of chronic otalgia, but it is necessary to consider the possible existence of more than one pathology and request routine neurological and dental consultations.
\end{abstract}

\section{Introduction}

Otalgia can be classified as otological (primary; otogenic) and non-otological (secondary; referred) [1]. Over half of the patients with otalgia have secondary Otalgia [2,3].

The ear has a complex innervation involving the $5^{\text {th }}, 7^{\text {th }}, 9^{\text {th }}$, and $10^{\text {th }}$ cranial nerves and $2^{\text {nd }}$ and $3^{\text {rd }}$ cervical plexus nerves. The first symptom of any pathology of these nerves may be secondary otalgia. The most frequent causes are dental pathologies, Temporomandibular Joint Disorders (TMD), Cervical Spine Disease (CSD), sinusitis, and tonsillitis/pharyngitis. Less commonly, various pathologies of the tongue and oral cavity, larynx, neck, thyroid, lungs, and heart may cause secondary otalgia. Consequently, secondary otalgia is an important symptom [3-6].

In a literature review of secondary otalgia, we found that no study separated it into acute versus chronic and all previous research approached otalgia in the same way. Only one study specifically considered CSD [3]. We believe that secondary otalgia needs to be evaluated separately as acute and chronic, as is done for all medical symptoms. Therefore, we evaluated chronic secondary otalgia using a multidisciplinary approach and determining its relationship to CSD.

\section{Otorhinolaryngology}

\author{
Mazlumoglu MR ${ }^{1 *}$, Kuduban $\mathrm{O}^{2}$, Duksal $\mathrm{T}^{3}$, Cetin $\mathrm{A}^{4}$ \\ and Sagsoz ME ${ }^{5}$
}

${ }^{\text {I} O t o l a r y n g o l o g y}$ Clinic, Hinis Sehit Yavuz Yurekseven State Hospital, Turkey

${ }^{2}$ Otolaryngology Clinic, Training and Research Hospital, Turkey ${ }^{3}$ Neurology Clinic, Hinis Sehit Yavuz Yurekseven State Hospital, Turkey

${ }^{4}$ Dentistry Clinic, Hinis Sehit Yavuz Yurekseven State Hospital, Turkey

${ }^{5}$ Department of Biophysics, Ataturk University, Turkey

\section{*Address for Correspondence}

Mazlumoglu MR, Otorhinolaryngology Clinic, Hinis Sehit Yavuz Yurekseven State Hospital, Erzurum, Turkey, Tel: +90 542435 5835; Fax: +90 0442327 3632; E-mail: dr.mazlumoglu@gmail.com

Submission: 24 April, 2017

Accepted: 17 May, 2017

Published: 25 May, 2017

Copyright: $\odot 2017$ Mazlumoglu MR, et al. This is an open access article distributed under the Creative Commons Attribution License, which permits unrestricted use, distribution, and reproduction in any medium, provided the original work is properly cited.

\section{Materials and Methods}

The study was conducted at Hinis State Hospital and Erzurum Region Education and Training Hospital, Erzurum, Turkey between May 2015 and January 2016, with approval of the regional ethics committee. We carried out a prospective clinical study.

The study enrolled 224 patients who visited otolaryngology clinics complaining of otalgia for more than 3 months in whom the otalgia was identified as secondary.

Patients presenting to the otolaryngology clinic with otalgia were first evaluated to determine if they had primary otalgia. Patients in whom primary otalgia was not identified underwent endoscopic evaluation of the nasal and oral cavities, oropharynx, nasopharynx, hypopharynx, and larynx. The neck and thyroid were examined. Imaging was obtained as deemed necessary. Then, each patient was referred to the neurology and dentistry clinics, where they underwent physical examinations, direct radiography, Computed Tomography (CT), and Magnetic Resonance imaging (MR) to identify dental, temporomandibular, and CSD conditions. Any patients who did not complete the evaluations at all three clinics were excluded from this study.

To accept CSD as an etiological factor in otalgia, we included pathologies above the $\mathrm{C} 4$ level. We classified these pathologies as cervical disc disease, osteo-degenerative changes, and other pathologies (stenosis, Chiari malformations, rheumatic diseases, etc.). Patients in whom no etiological factor was identified were diagnosed with psychogenic otalgia. We analyzed patient age and gender, pain localization (right, left, or bilateral), pain duration, any identified pathologies, and the results of diagnostic tests. The analyses were performed using SPSS 20 (IBM. Armonk, NY, USA). 
Citation: Mazlumoglu MR, Kuduban O, Duksal T, Cetin A, Sagsoz ME. Chronic Secondary Otalgia: Multidisciplinary Evaluation and Relationship with Cervical Spine Disease. Inter J Otorhinolaryngology. 2017;4(1): 3.

\section{Results}

The 224 patients enrolled this study included 148 women and 76 men $($ female/male ratio $=1.9)$. The age average of the patients was $41 \pm 18$ (range $7-75)$ years, $87 \%(n=195)$ were adults and $13 \%(n=29)$ were children. The pain was bilateral in $65.1 \%$ of the patients $(n=146)$, in the right ear in $17.9 \%(n=40)$, and in the left ear in $17 \%(n=38)$ (Table 1). The average duration of the otalgia was 11.2 months.

Chronic secondary otalgia was frequently seen in women and the middle-aged, but rarely in children. The pain was more often bilateral, and when unilateral there was no statistical difference $(\mathrm{p}<0.05)$ between right and left otalgia.

The most frequent etiological factors in chronic otalgia were CSD (49.1\%), TMD (32.1\%), dental pathologies (21.9\%), and chronic sinusitis (9.4\%). More than one pathology was identified in $31.3 \%$ of the patients (Table 2).

For the patients with CSD, cervical disc disease was found in $81.8 \%$, osteodegenerative disease in $46.3 \%$, and other pathologies (stenosis, Chiari malformation, and somatological diseases) in 19\%. More than one pathology of the cervical spine was found in $47.2 \%$ of the patients (Table 3). Of the patients identified with CSD, $81.6 \%$ underwent MRI and 18.4\% CT.

When we examined the relationship between etiological factors and age, the average age was 45.5 years for CSD, 38.5 years for TMD,

Table 1: Demographics and localization.

\begin{tabular}{|c|c|c|}
\hline & Frequency & Percent (\%) \\
\hline Child & 29 & 13 \\
Adult & 195 & 87 \\
\hline Male & 76 & 33,9 \\
Female & 148 & 66,1 \\
\hline Bilateral & 146 & 65,1 \\
Right & 40 & 17,9 \\
Left & 38 & 17 \\
\hline
\end{tabular}

Table 2: Etiologic factors.

\begin{tabular}{|c|c|c|}
\hline & Frequency & Percent (\%) \\
\hline Cervical spine disease (CSD) & 110 & 49,1 \\
\hline Temporomandibular joint disorders (TMD) & 72 & 32,1 \\
\hline Dental Pathology & 49 & 21,9 \\
\hline Chronic Sinusitis & 21 & 9,4 \\
\hline Myofascial Pain Syndrome & 6 & 2,7 \\
\hline Head and Neck Tumors & 3 & 1,3 \\
\hline Long Styloid Process & 2 & 0,9 \\
\hline Psychogenic & 9 & 4 \\
\hline Multiple Pathologies & 70 & 31,3 \\
\hline
\end{tabular}

Table 3: Distribution of cervical spine diseases.

\begin{tabular}{|c|c|c|}
\hline & Frequency & Percent (\%) \\
\hline Cervical Disc Disease & 90 & 81,8 \\
\hline Osteodegenerative Disease & 51 & 46,3 \\
\hline Other Cervical Spine Disease & 21 & 19 \\
\hline Multiple Pathologies & 52 & 47,2 \\
\hline
\end{tabular}

and 34.2 years for dental pathologies. Elderly patients are at a higher risk of CSD.

\section{Discussion}

The most frequent etiological factors in chronic secondary otalgia were CSD, TMD, dental pathologies, and chronic sinusitis.

The identification of primary otalgia is much easier than that of secondary otalgia and primary otalgia generally results from infections, tumors, and trauma involving the outer and middle ear. Primary otalgia is much more frequent in males than in females and more frequent in children than in adults. In comparison, secondary otalgia is much more frequent in females and adults [1-8]. We found that chronic secondary otalgia was much more frequent in females and adults.

In previous clinical studies of secondary otalgia, the most frequently reported causes were TMD and dental pathologies [4,712]. Kuttila et al. found that the most frequent cause was TMD for women and recurrent neck pain for men [4]. Sumitha et al. identified TMD in $36.9 \%$ of secondary otalgia and dental pathologies in $31.06 \%$ [11]. In comparison, Taziki et al. found dental pathologies in $62.8 \%$ of their patients. Jaber et al. specifically examined cervical pathologies and found that the most frequent causes were CSD, TMD, and dental pathologies that order, the same order that we identified. Although Kuttila et al. found that the most frequent cause of secondary otalgia in men was recurrent neck pain, they did not provide details. None of these studies involved routine dental and neurology consultations; none classified the symptoms as acute or chronic; and none searched for more than one etiological factor at the same time. Our study had each patient evaluated by an otolaryngologist, dentist, and neurologist and enrolled only patients with chronic otalgia; we also considered multiple etiologies. The prospective nature of this study also makes it superior to the other studies.

Less commonly, pathologies of the paranasal sinuses, pharynx, tongue, oral cavity, neck, thyroid, esophagus, heart, and lungs may cause secondary otalgia and otalgia may be the first symptom of malignity of this area $[13,14]$. Rarely, myocardial infarction, lung cancer, pyriform sinus fistula, tonsillitis, laryngocele, cervical spine meningioma, a laryngeal foreign object, or an ossifying stylohyoid ligament may cause secondary Otalgia [15-20]. Of our patients, 9.4\% had chronic sinusitis. Myofacial pain syndrome, a long styloid process, and head-neck malignancies were among the rare causes we identified in our series.

Otalgia should be managed using the following algorithm. In any patient presenting with otalgia, primary and secondary otalgia should be separated. This requires an otological examination and in certain cases, primary otalgia has to be eliminated by temporal bone CT. Then, the patient should be asked about the specifics of the pain, dental symptoms, concomitant nasal symptoms, previous surgery, upper aero digestive symptoms, and symptoms originating from the neck. Next, a detailed physical examination, including the neck, cervical spine, and temporomandibular joint, should be carried out, as well as endoscopic examinations of the nasal and oral cavities, teeth, oropharynx, nasopharynx, hypopharynx, and larynx. In some cases, areas that are not easily evaluated in the physical examination must be evaluated with CT or MR $[15,21,22]$. Finally, depending on 
Citation: Mazlumoglu MR, Kuduban O, Duksal T, Cetin A, Sagsoz ME. Chronic Secondary Otalgia: Multidisciplinary Evaluation and Relationship with Cervical Spine Disease. Inter J Otorhinolaryngology. 2017;4(1): 3.

the etiology of the secondary otalgia, referral to an otolaryngologist or related specialist is recommended [5,21]. We believe that there are additional steps that must be added to this algorithm.

Our findings were noteworthy in that CSD was the most frequent cause of chronic secondary otalgia and more than one etiology was frequently identified. Therefore, we believe that it is important to first separate secondary otalgia into acute and chronic and to routinely consult a neurologist and dentist.

\section{References}

1. Paparella MM, Shumrik DA, Gluckman JL (1991) Otolaryngology. Philadelphia: WB Saunders Co, 1237-1242

2. Neilan RE, Roland PS (2010) Otalgia. Med Clin North Am 94: 961-971.

3. Jaber JJ, Leonetti JP, Lawrason AE, Feustel PJ (2008) Cervical spine causes for referred otalgia. Otolaryngol Head Neck Surg 138: 479-485.

4. Kuttila SJ, Kuttila MH, Niemi PM, Le Bell YB, Alanen PJ, et al. (2001) Secondary otalgia in an adult population. Arch Otolaryngol Head Neck Surg 127: 401- 405

5. Charlett SD, Coatesworth AP (2007) Referred otalgia: a structured approach to diagnosis and treatment. Int J Clin Pract 61: 1015-1021.

6. Kim SH, Kim TH, Byun JY, Park MS, Yeo SG (2015) Clinical Differences in Types of Otalgia. J Audiol Otol 19: 34-38.

7. Reiss M, Pausch NC, Reiss G (2002) Etiology and diagnosis of otalgia. Wien Med Wochenschr 152: 613-617.

8. Yanagisawa K, Kveton JF (1992) Referred otalgia. Am J Otolaryngol 13: 323-327.

9. Kim DS, Cheang P, Dover S, Drake-Lee AB (2007) Dental otalgia. J Laryngol Otol 121: 1129-1134.
10. Taziki MH, Behnampour N (2012) A study of the etiology of referred otalgia. Iran J Otorhinolaryngol 24: 171-176.

11. Sumitha R, Joseph NA (2015) Referred otalgia - a case series. Asian. J Pharm Clin Res 8: 343-345. Leonetti JP, Li J, Donzelli J (1997) Otalgia in a normal appearing ear. Otolaryngol Head Neck Surg 117.

12. Shah RK, Blevins NH (2003) Otalgia. Otolaryngol Clin North Am 36: 1137 1151

13. Scarbrough TJ, Day TA, Williams TE, Hardin JH, Aguero EG, et al. (2003) Referred otalgia in head and neck cancer: a unifying schema. Am J Clin Oncol 26: 157-162.

14. Kuo YW, Chen KY, Chang YL, Lee LN, Yu CJ (2008) Small-cell lung carcinoma presenting with otalgia and hearing impairment. J Clin Oncol 26 : 4690-4692.

15. Gibbs CM, Nichols FC, Kasperbauer JL, Jensen EA, Farrugia G (2004) Meal-induced dysphagia and otalgia secondary to a pyriform sinus fistula. Dig Dis Sci 49: 1560-1562.

16. Kim KS (2013) Referred otalgia induced by a large tonsillolith. Korean J Fam Med 34: 221-223.

17. Danish SF, Zager EL (2005) Cervical spine meningioma presenting as otalgia: case report. Neurosurgery 56: E621.

18. Lau D, Watson D (1998) Referred otalgia: an unusual presentation of a laryngeal foreign body. Hosp Med 59: 161.

19. Riley N (1996) An unusual cause of otalgia--an ossified stylohyoid ligament Ir J Med Sci 165: 139.

20. Visvanathan V, Kelly G (2010) 12 minute consultation: an evidence-based management of referred otalgia. Clin Otolaryngol 35: 409-414.

21. Chen RC, Khorsandi AS, Shatzkes DR, Holliday RA (2009) The radiology of referred otalgia. AJNR Am J Neuroradiol 30: 1817-1823. 